\title{
AVALIAÇÃO DO POTENCIAL PEDAGÓGICO DE PAISAGENS PARA EDUCAÇÃO PATRIMONIAL NO ENSINO DE GEOGRAFIA
}

\author{
Márcia Evangelista Sousa ${ }^{1}$ \\ Lucas Costa de Souza Cavalcanti ${ }^{2}$
}

Resumo: O conceito de patrimônio é um tema fundamental para o fortalecimento da identidade e empoderamento comunitário. Neste sentido, o presente trabalho apresenta uma proposta de avaliação das paisagens para educação patrimonial, visando sobretudo a contribuição da Geografia, no reconhecimento do patrimônio local. A pesquisa foi desenvolvida no povoado do Flamengo, localizado no município de Jaguarari-BA. A avaliação do potencial pedagógico das paisagens foi conduzida por meio de levantamento bibliográfico da área de estudo e trabalhos de campo visando identificar elementos relevantes do patrimônio natural e cultural, que permitissem seu aproveitamento pedagógico. Assim, considerando a história de formação da comunidade, suas crenças, valores e relação com a terra, foram escolhidos os seguintes elementos relevantes: a Serra do Flamengo, o Cruzeiro, a Linha Férrea e a antiga Estação. A exploração didática desses elementos possibilita a abordagem de conteúdos geográficos diversos, principalmente, os que ressaltam a valorização do lugar e a relação sociedade-natureza. Deste modo, a utilização de paisagens para a realização de aulas de campo além de proporcionar maior compreensão dos conteúdos didáticos, permite também o conhecimento do lugar vivido, contribuindo assim, com a valorização e a conservação do patrimônio natural e cultural.

Palavras-chave: Ensino de Geografia. Educação patrimonial. Práticas de campo.

\section{EVALUATION OF PEDAGOGICAL POTENTIAL OF LANDSCAPES FOR EDUCATION OF HERITAGE AT THE TEACHING OF GEOGRAPHY}

\begin{abstract}
The concept of heritage is a fundamental theme for the strengthening of the identity and community empowerment. In this sense, the present paper presents an evaluation proposal of landscapes for heritage education, focusing mainly on the contribution of Geography, in the recognition of the local patrimony. The search was developed in the village of Flamengo, located in the municipality of Jaguarari-BA. The assessment of potential pedagogy of landscapes was conducted through a bibliographic survey of the study area and fieldwork aiming to identify relevant elements of natural and cultural heritage, that would allow their pedagogical use. Like this, considering the history of community formation, their beliefs, values and relationship with the earth, have been chosen the following relevant elements: the Saw of Flamengo, the Cruise, the Railway Line and the old station. The didactic exploration of these elements makes possible the approach of diverse geographic contents, mainly, those that emphasize the valorization of the place and the relation society-nature. In this way, the use of landscapes for the realization of field classes besides providing greater

\footnotetext{
${ }^{1}$ Mestra em Educação pela Universidade de Pernambuco. Professora de Geografia da Rede Municipal de Ensino de Petrolina-PE. Email: marah-sousa@ hotmail.com

${ }^{2}$ Professor adjunto da Universidade Federal de Pernambuco, Centro de Ciências Humanas, Departamento de Ciências Geográficas. Email: lucascavalcanti3@gmail.com
} 
understanding of the didactic contents, also allows the knowledge of the lived place, thus contributing, with the valorization and conservation of the natural and cultural patrimony.

Keywords: Teaching of Geography. Heritage Education. Field Practices.

\section{EVALUACIÓN DEL POTENCIAL PEDAGÓGICO DE PAISAJES PARA LA EDUCACIÓN PATRIMONIAL EN LA ENSEÑANZA DE GEOGRAFÍA}

Resumen: El concepto de patrimonio es un tema fundamental para el fortalecimiento de la identidad y empoderamiento comunitario. En este sentido, el presente trabajo presenta una propuesta de evaluación de los paisajes para educación patrimonial, visando sobre todo la contribución de la Geografía, en el reconocimiento del patrimonio local. La investigación fue desarrollada en el pueblo del Flamengo, ubicado en el municipio de Jaguarari-BA. La evaluación del potencial pedagógico de los paisajes fue conducida por medio de levantamiento bibliográfico del área de estudio y trabajos de campo para identificar elementos relevantes del patrimonio natural y cultural, que permitieran su aprovechamiento pedagógico. Así, considerando la historia de formación de la comunidad, sus creencias, valores y relación con la tierra, fueron escogidos los siguientes elementos relevantes: la Serra do Flamengo, el Cruzeiro, la Línea Férrea y la antigua Estación. La exploración didáctica de estos elementos posibilita el abordaje de contenidos geográficos diversos, principalmente, los que resaltan la valorización del lugar y la relación sociedad-naturaleza. De este modo, la utilización de paisajes para la realización de clases de campo además de proporcionar una mayor comprensión de los contenidos didácticos, permite también el conocimiento del lugar vivido, contribuyendo así, con la valorización y la conservación del patrimonio natural y cultural.

Palabras clave: Enseñanza de Geografía. Educación patrimonial. Prácticas de campo.

\section{Introdução}

No processo de fortalecimento identitário e empoderamento de comunidades rurais, o reconhecimento de valores históricos, sistemas de crenças e de reflexão das relações com a terra é um passo fundamental. O ensino de Geografia pode contribuir de modo crucial neste processo auxiliando o campo interdisciplinar da educação patrimonial.

$\mathrm{O}$ conceito de patrimônio pode ser entendido num sentido restrito e num sentido amplo. No primeiro caso, está relacionado às manifestações excepcionais da natureza e às produções da humanidade, seja no plano material ou imaterial. No segundo caso, refere-se aos elementos materiais e imateriais relevantes para a construção da identidade de um determinado grupo social. Neste sentido, o conceito de patrimônio atravessa campos disciplinares diversos e permite a elaboração de propostas pedagógicas interdisciplinares.

Pela ótica da Geografia, pode-se perceber que a paisagem figura como conceito e elemento guarda-chuva para construção de práticas pedagógicas ancoradas na realidade 
comunitária, tendo forte apelo educativo e utilitário para fomentar o interesse na valorização e conservação do patrimônio, seja ele natural ou cultural.

A Geografia por muito tempo foi conhecida como a disciplina da "decoreba", pois os conhecimentos geográficos resumiam-se em memorizar capitais e estados e/ou países, visto que nem mesmo a localização desses lugares eram explorados. Nesse contexto, os conhecimentos geográficos eram de aplicabilidade muito limitada, uma vez que não possibilitavam ao estudante investigar o mundo à sua volta, visto que o seu papel era apenas decorar os conceitos transmitidos por seus professores.

Sabe-se que o ensino de Geografia não se limita em apenas informar tipos de relevo nem mostrar diferentes projeções cartográficas, mas, sim, em apresentar o espaço geográfico e os elementos que o constitui, propiciando ao aluno a compreensão do espaço vivido. Também é função desse ensino demonstrar a relação homem e natureza, abordando os impactos causados pelas sociedades aos ambientes naturais.

Nesse seguimento, a Geografia possibilita compreender a interação dos indivíduos com os elementos da natureza, visto que a sobrevivência da humanidade depende essencialmente do uso dos recursos naturais. Por outro lado, é perceptível que a utilização desses recursos não ocorre de forma adequada, o que acaba prejudicando o meio ambiente. Assim, faz-se mister destacar os danos ocasionados ao planeta devido a realização das atividades antrópicas e as consequências aos ecossistemas.

Quanto ao ensino de Geografia, Belo e Ferreira (2012, p. 76) destacam que ele "se constitui como um instrumento capaz de mover o mundo, promovendo novas ações por meio da realização de novas práticas". Isso corrobora a relevância da Geografia, justificando a eficácia desse ensino na transformação do espaço e na formação dos indivíduos. Nessa perspectiva, Neves (2010, p.11) ressalta que "a vivência dos trabalhos de campo nas aulas de Geografia pode ser um importante aliado do educador ao contribuir para a construção do olhar geográfico dos estudantes”. Assim, a inserção de novas práticas de ensino permite maior desenvolvimento dos conhecimentos geográficos, ao mesmo tempo que instiga o senso crítico dos alunos contribuindo com a sua formação cidadã.

Essa formação cidadã condiz com o desenvolvimento de ações voltadas para preservação ambiental, tendo em vista que a maioria dos recursos naturais não são renováveis e que o manejo inadequado poderá originar danos catastróficos ao planeta. 
Diante do exposto, verifica-se a essencialidade da conservação das paisagens naturais, uma vez que elas apresentam grande vulnerabilidade à degradação ambiental, seja por fatores naturais ou pelas atividades antrópicas. Nesse sentido, algumas paisagens apresentam maior instabilidade, a exemplo das que estão inseridas em áreas semiáridas que sofrem alterações devido a interferência de fenômenos naturais, como a ausência de chuvas que reduz a cobertura vegetal, deixando o solo mais suscetível aos processos erosivos e, que associadas à ação humana pode ocasionar maior degradação, podendo levar algumas áreas a desertificação. Daí a necessidade de desenvolver práticas que visem à conservação dessas paisagens.

Com base nestas considerações, o trabalho teve como objetivo desenvolver uma proposta de avaliação pedagógica das paisagens, visando promover a educação patrimonial por meio do ensino de Geografia, mediante a realização de aulas de campo. Com isso, buscase maior efetivação de trabalhos de campo nas proximidades das escolas, no intuito de levar os estudantes a conhecer melhor o lugar que estão inseridos, e assim desenvolver o sentimento de pertencimento, uma vez que tal atitude contribui com medidas que promovem a conservação do patrimônio local.

\section{O ensino de Geografia e a conservação patrimonial}

O desenvolvimento de práticas de campo no ensino de Geografia é de fundamental importância para o conhecimento e preservação do patrimônio local, uma vez que é através da ida ao campo que o aluno vivencia na prática o que é apresentado nos livros didáticos, como também, é o momento ideal para conhecer melhor o lugar em que vive e quais elementos representam sua cultura.

Nesse âmbito, apresenta-se uma proposta pedagógica para o município de JaguarariBA (Figura 1), utilizando como laboratório de campo o povoado do Flamengo, visto que essa localidade apresenta inúmeros elementos que podem ser explorados nas aulas de Geografia. Assim, a utilização dessa paisagem para fins pedagógicos contribuirá com a difusão dos conteúdos geográficos, como também, possibilitará aos estudantes maior conhecimento do local em que vivem. Além do mais, proporcionará a identificação dos elementos que apresentam vulnerabilidade a degradação e possivelmente, a elaboração de medidas que possam minimizar os impactos ocasionados. 


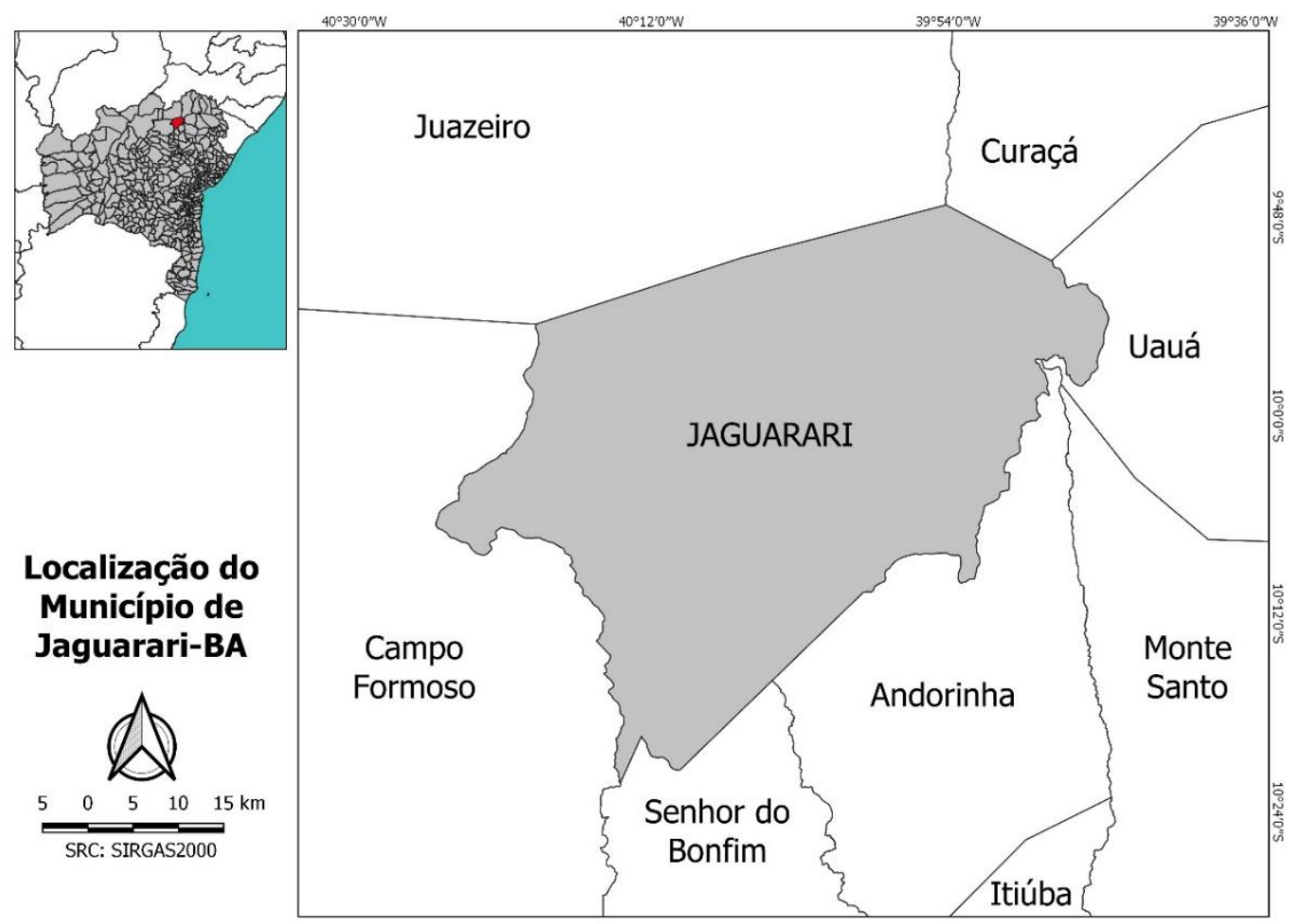

Figura 1: Localização do Município de Jaguarari-BA. Fonte: Cavalcanti, 2018.

Desse modo, o ensino de Geografia aliado a prática de campo, além de propiciar ao estudante a compreensão do espaço em que ele vive, auxilia consideravelmente na conservação deste, pois o discente perceberá melhor o ambiente que está inserido, identificando problemas e buscando possíveis soluções. Dessa forma, é primordial a excelência no trabalho docente para elaborar atividades que visem desenvolver o senso crítico dos alunos, tendo como foco atividades que busquem a valorização do local e a preservação do meio ambiente.

O presente trabalho visa demonstrar o potencial pedagógico do povoado do Flamengo e a contribuição do ensino de Geografia para a conservação e valorização do patrimônio natural e cultural. Uma vez que, esse ensino contribui para a proteção do patrimônio local, através da sensibilização dos alunos sobre a necessidade de valorizar e conservar os bens patrimoniais, que são representados por elementos naturais e culturais.

Nesse sentido, ressalta-se a significância da escola trabalhar a preservação ambiental, destacando os impactos ocasionados pela extração dos recursos naturais de forma inadequada. Do mesmo modo, faz-se mister abordar os elementos que simbolizam a cultura local pois eles 
revelam a história e a identidade de uma comunidade, visto que muitos costumes se perdem no tempo por falta de conhecimento e valorização por parte de seus habitantes, sobretudo quando são influenciados por elementos culturais externos.

Esta pesquisa também enfatiza a necessidade de conservar as paisagens naturais, uma vez que a extração de recursos naturais dificilmente ocorre de maneira adequada, levando a degradação ambiental. Diante disso, destaca-se os principais aspectos normativos para a conservação do patrimônio natural propostos pela Constituição Federal, através da Política Nacional do Meio Ambiente, além de evidenciar a importância da educação para a preservação do meio ambiente.

Os princípios de geoconservação também são abordados, uma vez que são medidas que tem por objetivo conservar e proteger elementos geológicos significativos. Dentre estas medidas, destaca-se o turismo de natureza e pedagógico como atividades que proporcionam a conservação das paisagens, ao mesmo tempo que contribui com o dinamismo das aulas de Geografia, propiciando ao aluno a vivência dos conteúdos e a sensibilização perante a degradação patrimonial.

De acordo com o Delphim (2004), a preservação do patrimônio natural permite que os elementos físicos e biológicos se integrem de forma harmônica, coexistindo de maneira equilibrada com as ações humanas, no entanto, a sua valorização resulta impreterivelmente do nível de conhecimento das formas de utilização que se faz desse patrimônio. Assim, utilizar os recursos de forma consciente é uma medida bastante eficaz para preservar a natureza, exigindo a sensibilização da população local.

De acordo com o artigo $2^{\circ}$ da Convenção para a Proteção do Patrimônio Mundial, Cultural e Natural, considera-se como patrimônio natural:

\footnotetext{
Os monumentos naturais constituídos por formações físicas e biológicas ou por grupos de tais formações com valor universal excepcional do ponto de vista estético ou científico;

As formações geológicas e fisiográficas e as zonas estritamente delimitadas que constituem habitat de espécies animais e vegetais ameaçadas, com valor universal excepcional do ponto de vista da ciência ou da conservação;

Os locais de interesse naturais ou zonas naturais estritamente delimitadas, com valor universal excepcional do ponto de vista da ciência, conservação ou beleza natural. (UNESCO, 1972, p. 2).
}

Sendo assim, é perceptível que o patrimônio natural abrange tanto a biodiversidade quanto a geodiversidade, ou seja, ele é composto por elementos biótico e abiótico, e ambos 
mantêm grande relação. Entretanto, é bastante comum encontrar áreas naturais muito alteradas devido ao mau uso do solo, visto que quando a sua utilização não ocorre de maneira sustentável ocasiona sérios danos ao patrimônio natural. Dessa forma, a elaboração de medidas que visem minimizar esses impactos torna-se uma grande alternativa para mitigar a degradação ambiental.

\section{Da Geoconservação à Educação Patrimonial}

Um dos grandes desafios para a ampliação do diálogo e aplicações do conceito de patrimônio na educação é a necessidade de fazer convergir esforços provenientes de áreas distintas, como a história, o turismo de natureza, a educação ambiental e a geoconservação.

Entende-se por geoconservação as medidas que visam conservar e proteger o patrimônio geológico, e tem como objetivo "a utilização e gestão sustentável de toda a geodiversidade, englobando todo o tipo de recursos geológicos" (BRILHA, 2005, p. 51). A geoconservação também possibilita a sensibilização das pessoas sobre a importância de proteger e valorizar os elementos abióticos do planeta (BRILHA; DIAS; PEREIRA, 2006), uma vez que esses recursos precisam ser manejados adequadamente, pois podem tornar-se escassos.

A conservação do patrimônio natural é primordial para manter o equilíbrio dos ecossistemas, uma vez que estes dependem da interação constante dos elementos naturais para dar continuidade ao ciclo ecológico. Daí a necessidade do desenvolvimento de práticas que visem a permanência do funcionamento da natureza, envolvendo tanto os elementos biológicos como os geológicos.

Diante disso, Bento e Araújo (2014) destacam algumas formas que poderão ajudar no reconhecimento da potencialidade e da importância dos recursos naturais, sendo uma dessas, o uso do geoturismo como instrumento pedagógico para valorização do patrimônio. Assim, as autoras supracitadas apresentam a escola como item fundamental para divulgação da geodiversidade, uma vez que esta possibilitará aos alunos o conhecimento de conceitos na área, além de desenvolver maior percepção sobre o patrimônio geológico, como também tornará as aulas de Geografia mais dinâmicas e atrativas.

Dessa forma, o turismo de natureza (Figura 2) é apresentado com várias vertentes como: geoturismo, geoecoturismo, ecoturismo, turismo pedagógico, turismo de aventura, 
entre outros. Essas modalidades turísticas proporcionam maior contato com a natureza ao mesmo tempo que permitem aos visitantes conhecer a importância dos elementos biológicos e geológicos para o funcionamento da dinâmica natural e a necessidade de conservá-los.

Em relação ao geoturismo, Bento (2011) afirma que ele surgiu na década de $1990 \mathrm{em}$ decorrência da carência de divulgar, preservar e valorizar o patrimônio natural abiótico, assim, essa atividade tem como objetivo principal a conservação da geodiversidade, visto que a maioria das ações que visam a proteção ambiental estão voltadas para a preservação da biodiversidade.

Nesse sentido, o geoturismo é "um novo segmento do turismo caracterizado por ter o patrimônio geológico como principal atrativo, e que, através de atividades de interpretação ambiental busca a compreensão dos fenômenos geológico-geomorfológicos atuantes no local visitado" (LOPES; ARAÚJO; CASTRO, 2011, p. 1). No entanto, ele diferencia-se do ecoturismo em decorrência deste último priorizar apenas a biodiversidade, deixando de lado os aspectos geológicos, contudo, os dois exercem critérios e métodos de sustentabilidade (MOREIRA, 2010).

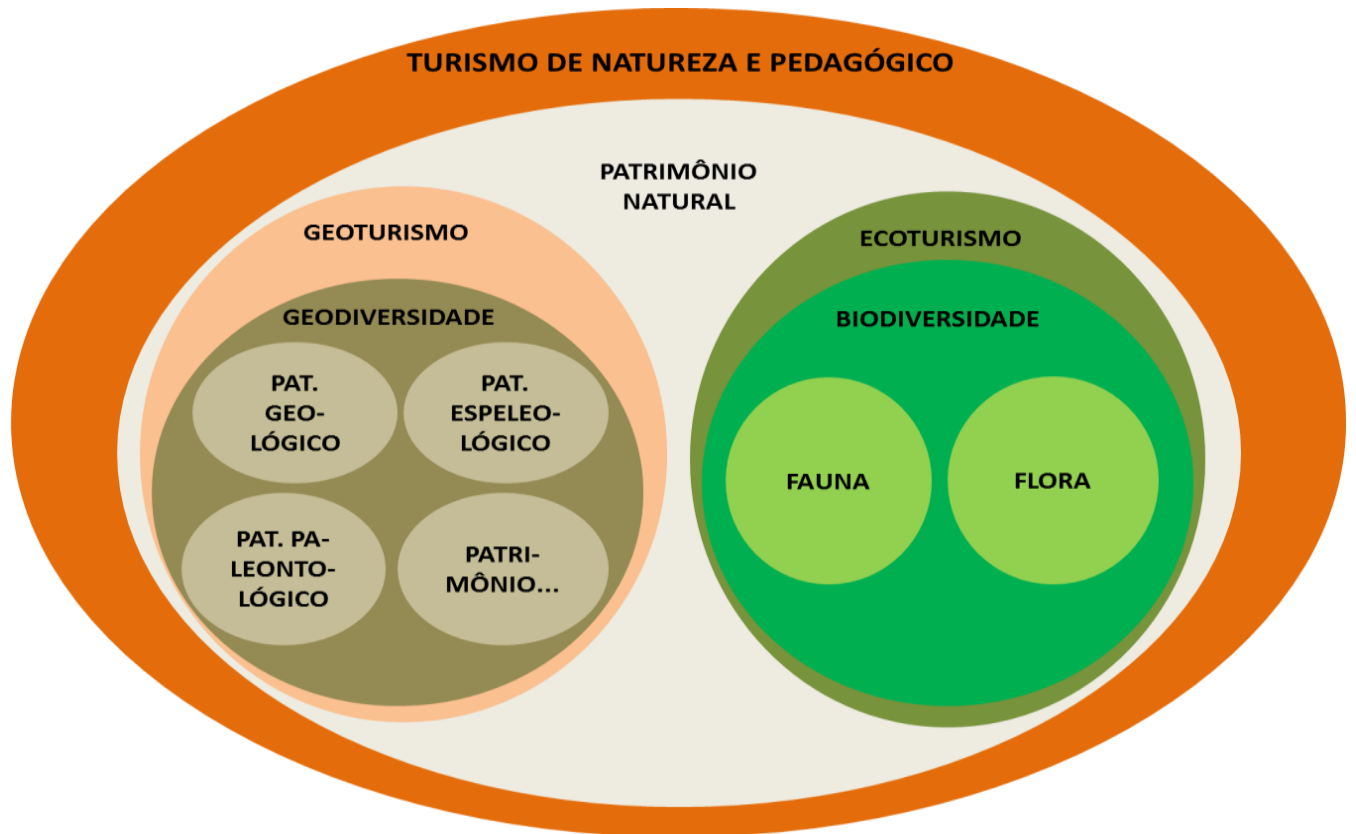

Figura 2: Esquema ilustrativo das formas de turismo de natureza e pedagógico. Fonte: Adaptado de Bento 2011.

De acordo com Bento (2011), a implantação do geoturismo promove a geoconservação, ou seja, favorecerá a conservação dos elementos abióticos, já que o mais 
comum é a valorização e divulgação da biodiversidade. Além disso, essa atividade contribuirá para a aplicação e compreensão dos conteúdos pedagógicos, pois, segundo Bento e Araújo (2014, p. 135) "o uso do geoturismo para fins didáticos contribui também para o enriquecimento das aulas de geografia, pois, dinamiza o aprendizado proporcionando a ligação entre a teoria e a prática do trabalho de campo".

Nesse âmbito, as autoras citadas ressaltam que o turismo pedagógico oferece aos alunos maior percepção da paisagem, proporcionando a eles um aprofundado conhecimento sobre os elementos abióticos, promovendo também a conscientização sobre a importância da geodiversidade, e assim contribuindo com a preservação do patrimônio natural.

A geoconservação poderá ocorrer também pela criação de áreas de preservação ambiental, e pela criação de geoparques. Esse último, destaca-se por promover a sustentabilidade econômica da população local através do geoturismo e do desenvolvimento de projetos educacionais (BACCI et al., 2009). Dessa forma, Nascimento; Ruchkys e Mantesso-Neto (2007), enfatizam o Programa de Geoparques desenvolvido pela UNESCO e sua grande expansão nos países europeus e na China, o qual tem como objetivo conservar e valorizar o patrimônio geológico. Nessa perspectiva, o Brasil foi contemplado com seu primeiro geoparque em 2006, o Geoparque Araripe, localizado no Estado do Ceará, reconhecido pela UNESCO nesse mesmo ano (BACCI et al., 2009).

Nesse sentido, Bacci et al. (2009) destacam que para a implantação de um geoparque verifica-se a excepcionalidade dos elementos geológicos e paleontológicos, uma vez que a quantidade e a beleza deles proporcionarão o desenvolvimento do geoturismo e melhorias na economia local, contemplando os três pontos de sustentação desse método, que são a conservação, a educação e o geoturismo.

No âmbito da legislação brasileira, o artigo $2^{\circ}$ da Constituição Federal apresenta a Política Nacional do Meio Ambiente, a qual tem como objetivo a preservação do meio ambiente, e destaca alguns princípios, entre eles, o Inciso X que assinala a "educação ambiental a todos os níveis de ensino, inclusive a educação da comunidade, objetivando capacitá-la para participação ativa na defesa do meio ambiente” (BRASIL, 1981, p. 1).

Isso ressalta a importância da educação para a conservação do patrimônio natural, devendo ocorrer em todos os níveis de ensino, para que desenvolva maior sensibilização da população e, consequentemente, a prática de atividades que visem a sustentabilidade do planeta. Inclusive a UNESCO (1994) criou um programa educacional voltado para a 
conservação do patrimônio natural, o qual busca envolver jovens na proteção do patrimônio natural a nível global.

Almejando desenvolver maior preservação do meio ambiente, foi criada a Lei $\mathrm{N}^{\circ}$ 9.985, de 18 de julho de 2000, o SNUC - Sistema Nacional de Unidades de Conservação da Natureza, que "estabelece critérios e normas para a criação, implantação e gestão das unidades de conservação" (Art. $1^{\circ}$, p. 1). Essa Lei tem como objetivos:

\footnotetext{
I - contribuir para a manutenção da diversidade biológica e dos recursos genéticos no território nacional e nas águas jurisdicionais;

II - proteger as espécies ameaçadas de extinção no âmbito regional e nacional;

III - contribuir para a preservação e a restauração da diversidade de ecossistemas naturais;

IV - promover o desenvolvimento sustentável a partir dos recursos naturais;

$\mathrm{V}$ - promover a utilização dos princípios e práticas de conservação da natureza no processo de desenvolvimento;

VI - proteger paisagens naturais e pouco alteradas de notável beleza cênica;

VII - proteger as características relevantes de natureza geológica, geomorfológica, espeleológica, arqueológica, paleontológica e cultural;

VIII - proteger e recuperar recursos hídricos e edáficos;

IX - recuperar ou restaurar ecossistemas degradados;

$\mathrm{X}$ - proporcionar meios e incentivos para atividades de pesquisa científica, estudos e monitoramento ambiental;

XI - valorizar econômica e socialmente a diversidade biológica;

XII - favorecer condições e promover a educação e interpretação ambiental, a recreação em contato com a natureza e o turismo ecológico;

XIII - proteger os recursos naturais necessários à subsistência de populações tradicionais, respeitando e valorizando seu conhecimento e sua cultura e promovendo-as social e economicamente (BRASIL, 2000, p. 2-3).
}

Logo, a criação de Leis ambientais é de grande relevância para a preservação do patrimônio natural, tendo como finalidade garantir o equilíbrio dos ecossistemas. No entanto, sabe-se que, em alguns casos a proteção de áreas naturais não ocorre por que é barrada em decorrência de interesses econômicos (DELPHIM, 2004), ou seja, os lucros financeiros sobrepõem a necessidade de preservação dos recursos naturais, o que poderá ocasionar no futuro a escassez de matéria-prima.

Bento e Araújo (2014) chamam atenção sobre a ocorrência da grande valorização da biodiversidade, uma vez que a maior parte dos estudos e das Unidades de Conservação visam a proteção dos elementos bióticos, deixando de lado a divulgação e preservação do meio abiótico. Sobre isso, Lopes e Araújo (2011) também enfatizam a ocorrência do desequilíbrio nos estudos e divulgação entre a preservação da biodiversidade e da geodiversidade. Isso condiz com a maior percepção que a humanidade tem dos seres vivos, no entanto, devê-loiam ter conhecimento de que "a geodiversidade é o resultado dos processos interativos entre a 
paisagem, a fauna, a flora e a nossa cultura" (LOPES; ARAÚJO, 2011, p. 67), visto que os aspectos geológicos apresentam relevância tanto quanto os elementos biológicos.

\section{Patrimônio cultural e seus elementos}

O patrimônio cultural é formado por bens que representam os costumes, os saberes e a história da formação de uma população. Em relação ao patrimônio brasileiro, Delphim (2004) ressalta que a legislação considera que o patrimônio histórico e artístico nacional é formado pelo conjunto de bens móveis e imóveis que são encontrados no país. Nesse sentido, o Instituto do Patrimônio Histórico e Artístico Nacional - IPHAN, apresenta como bens móveis coleções arqueológicas, acervos bibliográficos, esculturas, etc. e como bens imóveis cidades históricas, sítios arqueológicos e paisagísticos, patrimônio ferroviário, entre outros.

Segundo o Instituto do Patrimônio Histórico e Artístico Nacional - IPHAN, o patrimônio cultural divide-se em patrimônio material, arqueológico e imaterial. Dessa forma, o IPHAN (2015) define o patrimônio material como um conjunto de bens culturais e são categorizados de acordo com os critérios apresentados nos quatro Livros do Tombo. O primeiro desses livros aborda o patrimônio arqueológico, paisagístico e etnográfico, o segundo o patrimônio histórico, o terceiro as belas artes enquanto o quarto livro, as artes aplicadas.

Diante disso, o IPHAN (2015) descreve que o patrimônio arqueológico é formado por todos os bens de natureza arqueológica, como os lugares que apresentam vestígios de ocupação humana, a exemplo de sítios identificados como cemitérios, abrigos sob rochas, inscrições rupestres e os sambaquis. Em relação ao patrimônio imaterial, o referido Instituto ressalta que ele diz respeito às práticas e costumes da sociedade manifestados por meio de seus saberes, atividades e cultos. Assim, tem-se como exemplos, a linguajem, o folclore e os costumes.

Diante do grande valor que esses elementos simbolizam para a população, criaram-se medidas que buscam a conservação desses, dentre os quais, a educação patrimonial, uma vez que eles representam a identidade e a memória de uma comunidade. Sobre isso, Florêncio et al. (2014, p.19) afirmam que: "nos últimos anos, multiplicaram-se iniciativas educacionais voltadas à preservação patrimonial" surgindo várias medidas que visam valorizar, preservar e conservar o patrimônio cultural. 
Entre essas medidas de conservação do patrimônio cultural, estão os projetos desenvolvidos pelo Instituto do Patrimônio Histórico e Artístico Nacional - IPHAN, a exemplo do Projeto Casas do Patrimônio. Esta proposta tem como regimento conduzir as ações de Educação Patrimonial, que envolve aprofundamentos teóricos e avaliações das práticas educativas voltadas à preservação do patrimônio cultural. Além disso, a iniciativa também envolve as comunidades, as quais devem ser participantes ativas das ações educativas.

\section{Procedimentos metodológicos}

Na busca pela construção de uma proposta de avaliação do potencial pedagógico das paisagens, a estratégia adotada neste trabalho baseou-se em dois pontos principais, a saber: revisão bibliográfica e documental sobre a área de estudo e visita à campo para diagnóstico do potencial pedagógico.

Paralelamente, o levantamento bibliográfico sobre o tema abordado, buscou fundamentar a compreensão sobre o papel da Geografia para conservação do patrimônio natural e cultural. Dessa forma, buscou-se na literatura científica medidas que propiciam a conservação patrimonial por meio do ensino de Geografia. Além disso, verificou-se como a legislação brasileira aborda a preservação ambiental e os princípios que visam proteger os monumentos que representam a cultura nacional.

Em seguida, realizou-se a coleta de informações sobre a área de estudo, por meio da leitura de artigos, livros e trabalhos de conclusão de curso. Também foram avaliadas imagens de satélites disponíveis no Google Earth e mapas temáticos (principalmente geologia e geomorfologia) para aquisição de maiores informações sobre a região.

Posteriormente, conduziu-se um levantamento em campo para elencar os elementos que constituem o patrimônio local e destacar os atributos que podem ser explorados em aulas de campo, em especial, os que constituem objeto de estudo da Ciência Geográfica. O critério de inclusão dos elementos da paisagem como relevantes para o patrimônio local foi, principalmente, o reconhecimento pela população do sentido histórico, estético e simbólico. De outro modo, considerou-se também aspectos não indicados pela população, mas com potencial relevante para o ensino de Geografia. Diante disso, foram escolhidos os seguintes elementos relevantes: a Serra do Flamengo, o Cruzeiro, a Linha Férrea e a antiga Estação de 
Trem. A partir disso, elencou-se os principais atributos que podem ser explorados durante as aulas de campo pelas escolas da região, buscando instigar o reconhecimento e a conservação do patrimônio local.

\section{Resultados e discussão}

As paisagens avaliadas encontram-se no município de Jaguarari-BA, mais especificamente no povoado do Flamengo. Este município está situado no semiárido nordestino, apresentando baixos índices pluviométricos e altas temperaturas. Em decorrência das condições climáticas, a vegetação dominante é a caatinga, uma vez que ela é constituída por espécies adaptadas ao clima quente e seco.

O Flamengo e o seu entorno são marcados pela presença de serras, com cristas quartzíticas de formação geológica pré-cambriana e altitudes que podem chegar a $800 \mathrm{~m}$ (SOUSA, 2013). Em relação aos aspectos geomorfológicos, essa localidade apresenta várias feições geomorfológicas, entre elas, serras, inselbergues, depósito de tálus e pedimentos, como mostra a figura 3. Essas paisagens apresentam grande valor pedagógico, constituindo um bom exemplo para a explanação das formas de relevo.

É possível explorar outros atributos da paisagem como o metamorfismo, o solo e a ação intempérica. A interferência do intemperismo nessa região é bastante nítida, principalmente, pela meteorização mecânica, sendo bastante visível a presença de blocos rochosos fraturados devido a ação da temperatura (termoclastia) que provoca a dilatação dos minerais e, consequentemente, o fraturamento das rochas (JATOBÁ e LINS, 2008). Esse fator associado a erosão pluvial contribui para o aumento do depósito de tálus, que é o acúmulo de materiais (fragmentos rochosos) no sopé da encosta.

Outro conteúdo que pode ser explorado é a hidrografia local, sendo representada por um curso fluvial efêmero, onde deve ser enfatizado a importância da conservação da mata ciliar e os danos ambientais causados pelos resíduos sólidos. 


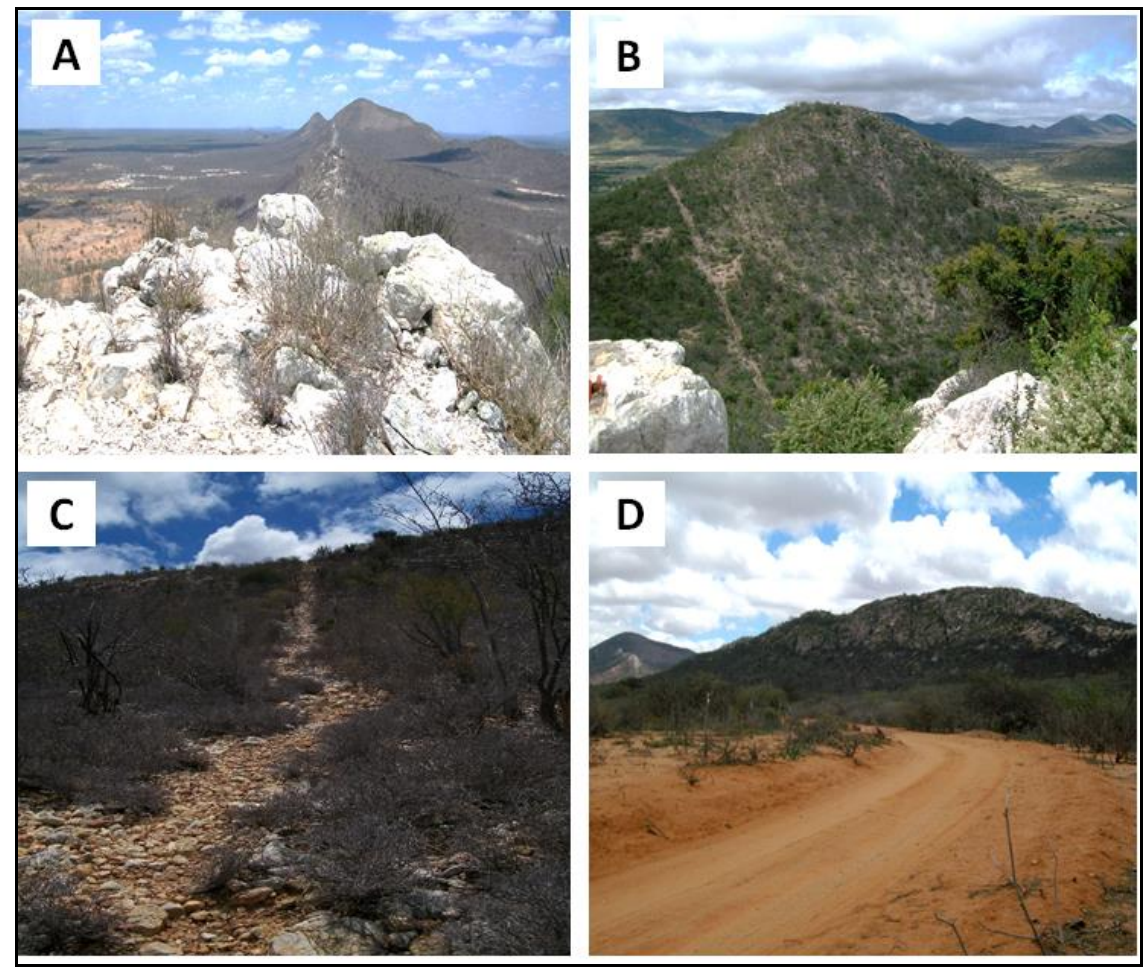

Figura 3: Feições geomorfológicos do Flamengo (A)Serra; (B) Inselbergue; (C) Depósito de tálus; (D) Pedimento.

Fonte: Sousa, 2015.

Em relação a vegetação, pode-se averiguar diversas plantas da caatinga, sendo possível encontrar várias espécies das famílias cactáceas e bromeliáceas, além da presença de árvores típicas desse bioma como: a catingueira (Caesalpinia pyramidalis), o angico (Anadenanthera macrocarpa), o umbuzeiro (Spondias tuberosa L.) e o pinhão bravo (Jatropha mollissima).

Com base no levantamento dos elementos presente nessas paisagens, verifica-se a possibilidade de abordar conteúdos geográficos diversos, tornando o entorno da escola um laboratório para os alunos. Com isso, pode-se ressaltar a interação dos elementos biótico e abióticos, a exemplo da relação presente entre a vegetação e o solo, podendo constatar que nas áreas mais elevadas onde predomina maior quantidade de rochas e consequentemente o solo é mais raso e pedregoso evidencia a presença de plantas de baixo porte, enquanto nas áreas de solo mais profundo a exemplo das proximidades do curso fluvial, há ocorrência de plantas de porte maior, principalmente arbustos.

Além dos aspectos naturais da paisagem, os elementos culturais são atributos que podem ser explorados didaticamente enriquecendo as aulas de Geografia, uma vez que 
promove o reconhecimento e a valorização da cultura local. Em relação ao povoado do Flamengo, o seu patrimônio cultural (figura 4) é formado por bens materiais e imateriais, pois apresenta elementos de valor econômico e simbólico, representados pela linha férrea, pela estação ferroviária e pelo cruzeiro. Esses elementos simbólicos contribuíram para a formação dessa localidade e expressam significativamente tanto a religiosidade, como a memória da comunidade.

Esses bens compõem o patrimônio cultural, uma vez que ajudam a retratar a identidade da população local, ou seja, eles manifestam a história dos habitantes do povoado do Flamengo. Por isso, a exploração didática desses elementos é de grande relevância para a comunidade, pois evidencia a evolução da paisagem no decorrer do tempo, uma vez que suas marcas registram a transformação do espaço.

A linha férrea contribuiu imprescindivelmente para a formação do Povoado Flamengo, pois segundo o IBGE (1954), a malha ferroviária foi primordial na constituição de vilas, povoados e cidades durante o século XIX e XX. No entanto, essa linha férrea hoje encontra-se quase que totalmente desativada, enquanto a Estação vivencia uma depredação acentuada.
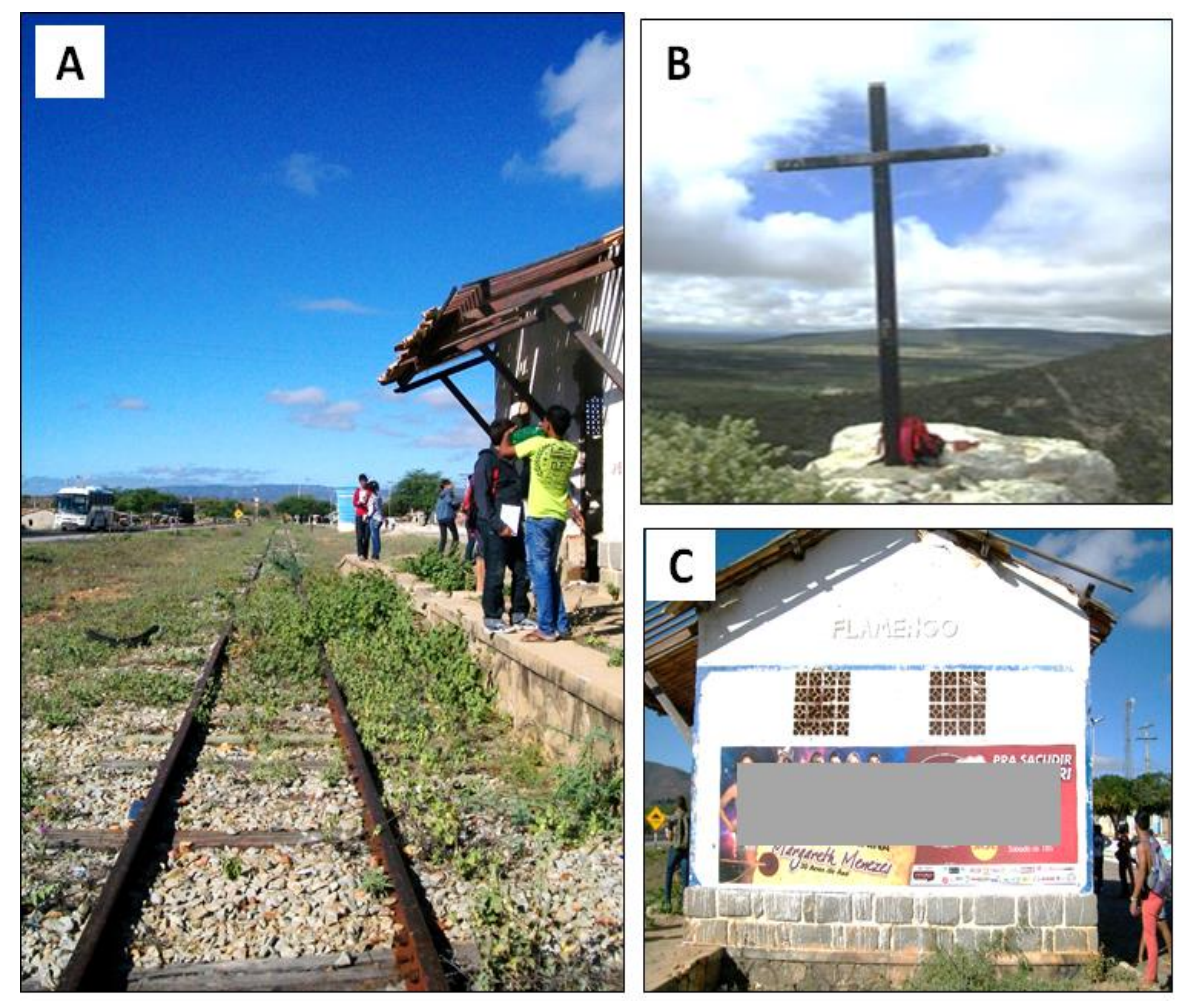

Figura 4: Patrimônio cultural do Flamengo. (A) Linha Férrea; (B) Cruzeiro; (C) Estação. Fonte: SOUSA, 2015. 
Essa ferrovia tem estação inicial no município de Salvador, no bairro de Calçada, onde situa a sua sede, distando aproximadamente $430 \mathrm{~km}$ do povoado do Flamengo. Ela foi a $5^{\mathrm{a}}$ ferrovia construída no Brasil, sendo inaugurada no ano de 1860. A linha principal dessa ferrovia parte da Estação de Calçada e vai até Juazeiro na Bahia, constituindo um trajeto de 570 km. O primeiro trecho partia da Estação de Calçada até Paripe, ambos em Salvador. Em seguida, outros trechos foram construídos, sendo o último, o trajeto de Senhor do Bonfim a Juazeiro, inaugurado em 1896. Com o tempo, ela passou a ligar os estados de Piauí, Pernambuco, Sergipe, Bahia e Minas Gerais (IBGE, 1954; SANTURIAN, 1991).

A estação construída no final do século XIX, parece ter perdido seu sentido patrimonial juntamente com a finalidade para qual foi construída. Tornou-se alvo de vândalos e, encontra-se sem portas, sem janelas e o teto com telhas soltas e quebradas. Hoje, esse legado encontra-se abandonado, apagando as marcas de uma trajetória que contribuiu significativamente para o povoamento do local. Diante disso, ressalta-se a significância do ensino de Geografia para a conservação e valorização do patrimônio por meio da realização de aulas de campo, visto que tal medida proporcionaria aos discentes conhecer o valor simbólico desses elementos para a formação histórica e socioespacial da localidade.

O outro elemento cultural do Flamengo está representado pelo cruzeiro, que fica no topo da serra, e marca um ponto de peregrinação, principalmente, durante a Semana Santa. Os fiéis buscam o local principalmente para realizar orações, coexistindo a relação do simbolismo religioso com as paisagens naturais. Isso justifica a importância desse bem para a população.

Pode-se também enfatizar a relação sociedade-natureza nessa paisagem, ressaltando a importância dos recursos naturais para a sobrevivência humana, como: o uso da terra para a agricultura, pecuária e extração de minerais. Também deve-se abordar a utilização da água do subsolo para o abastecimento da comunidade local, assim como os procedimentos usados para a retirada e armazenamento desse bem vital. Essa abordagem possibilita ao estudante conhecer a importância desses recursos para sua subsistência e ao mesmo tempo reconhecer que eles não são renováveis, por isso precisam ser conservados.

É importante frisar a extração de rochas nessa região, tornando-se uma atividade econômica do município, mas que poderá trazer danos irreparáveis a paisagem, pois a retirada 
dos minerais ocasiona a depredação do ambiente, visto que muitos afloramentos deixarão de existir com a permanência da extração.

Portanto, o uso das paisagens para a realização de aulas de campo é de fundamental relevância, uma vez que essa metodologia além de proporcionar maior compreensão dos conteúdos didáticos, evidencia a relação dos indivíduos com o espaço geográfico. E para obtenção de melhores resultados é aconselhável a realização de aulas interdisciplinares, uma vez que possibilita maior exploração dos elementos da paisagem tornando o processo de ensino-aprendizagem mais eficaz.

Deste modo, vale ressaltar a importância do ensino de Geografia para a percepção do espaço vivido, uma vez que essa disciplina propicia ao aluno a observação e a análise do mundo ao seu redor, contribuindo grandiosamente para o desenvolvimento de práticas que visam valorizar e conservar o patrimônio natural e cultural.

\section{Considerações finais}

Diante do exposto, percebe-se que o ensino de Geografia pode contribuir com a conservação do patrimônio natural e cultural, uma vez que oferece aos estudantes o conhecimento dos elementos que constituem o patrimônio local, ao mesmo tempo que demonstra a importância de conservar e valorizar os bens patrimoniais.

Deste modo, espera-se com a apresentação dessa proposta pedagógica uma maior realização de aulas de campo que visem promover o conhecimento do patrimônio local e a sua conservação. Também, almeja-se maior dinamismo das aulas de Geografia ao mesmo tempo em que busca desmistificar a ideia de disciplina monótona com aulas tediosas e cansativas.

O trabalho evidencia que as aulas de Geografia vão além da simples transmissão de conceitos geográficos, uma vez que ela permite despertar o aluno para compreender o mundo ao seu redor, participando ativamente na formação social dos indivíduos. Diante disso, podese inferir que este ensino atrelado a realidade do aluno poderá apresentar resultados bastante satisfatório, contribuindo de modo exitoso para o desenvolvimento de práticas sociais, principalmente, para a proteção patrimonial.

\section{Referências bibliográficas}


BACCI, D. de La C.; PIRANHA, J. M.; BOGGIANI, P. C.; LAMA, E. A. D.; TEIXEIRA, W. Geoparque: Estratégia de Geoconservação e Projetos Educacionais. Revista do Instituto de Geociências - USP. Geol. USP, Publ. Espec., São Paulo, v. 5, p. 7-15, out. 2009. Disponível em: < http://www.revistas.usp.br/gusppe/article/view/45386>. Acesso em: 28 mai. 2015.

BELO, Evelyn Monari; FERREIRA, Gustavo Henrique Cepolini. A importância da geografia em sala de aula: o desafio de um ensino capaz de formar o cidadão. Linguagem Acadêmica, Batatais, v. 2, n. 2, p. 65-82, jul./dez. 2012. Disponível em: <

file:///C:/Users/GT/Downloads/sumario5.pdf>. Acesso em: 20 mai. 2015.

BENTO, Lilian Carla Moreira. Um novo olhar para a geodiversidade através do geoturismo. ENCICLOPÉDIA BIOSFERA, Centro Científico Conhecer - Goiânia, vol.7, n.12; p. 159166. 2011. Disponível em: < http://www.conhecer.org.br/enciclop/conbras1/um\%20novo\%20olhar\%20para\%20a\%20geodi versidade.pdf $>$. Acesso em: 05 jun. 2015.

BENTO, Lilian Carla Moreira; ARAÚJO, Marina Silva. Geoturismo e geoconservação: uma prática de campo. In: I SIMPÓSIO MINEIRO DE GEOGRAFIA - Alfenas 26 a 30 de maio de 2014. Anais de resumo, p. 132-145. Disponível em: < http://www.unifal-

mg.edu.br/simgeo/system/files/anexos/Lilian\%20Carla\%20M.\%20Bento.pdf >. Acesso em: 05 jun. 2015.

BONFIM, Mailane Vinhas de Souza. Por uma pedagogia diferenciada: Uma reflexão acerca do turismo pedagógico como prática educativa. Revista Turismo Visão e Ação - Eletrônica, v. $12, \mathrm{n}^{\circ} 1$. p. 114 - 129, jan/abr. 2010. Disponível em: <

https://siaiap32.univali.br/seer/index.php/rtva/article/viewFile/1127/1511>. Acesso em: 02 jun. 2015.

BRASIL. Lei No 6.938, de 31 de agosto de 1981. Dispõe sobre a Política Nacional do Meio Ambiente, seus fins e mecanismos de formulação e aplicação, e dá outras providências.

Presidência da República. Disponível em:

<http://www.planalto.gov.br/ccivil_03/Leis/L6938.htm>. Acesso em: 09 mai. 2015.

BRASIL. Lei No 9.985, De 18 de julho de 2000. Regulamenta o art. 225, § 1o, incisos I, II, III e VII da Constituição Federal, institui o Sistema Nacional de Unidades de Conservação da Natureza e dá outras providências. Presidência da República. Disponível em:

<http://www.mma.gov.br/port/conama/legiabre.cfm?codlegi=322>. Acesso em: 09 mai. 2015. BRASIL. Ministério da Educação. Educação Patrimonial. Programa Mais Educação.

IPHAN - Instituto do Patrimônio Histórico e Artístico Nacional. Disponível em:

<http://portal.iphan.gov.br/uploads/publicacao/EduPat_EducPatrimonialProgramaMai sEducacao_fas1_m.pdf $>$. Acesso em: 09 mai. 2015.

BRILHA, José; DIAS, Graciete; PEREIRA, Diamantino. A Geoconservação e o Ensino/aprendizagem da Geologia. In: Simpósio Ibérico do Ensino da Geologia, XIV Simpósio sobre Enseñanza de La Geología, XXVI Curso de Actualização de Professores de Geociências. Universidade de Aveiro, Livro de Actas, 2006, p. 445-448. Disponível em:<https://repositorium.sdum.uminho.pt/bitstream/1822/5368/1/brilha_dias_pereira_sieg.pdf $>$. Acesso em: 14 jun. 2015.

BRILHA, José. Patrimônio Geológico e Geoconservação: A Conservação da Natureza na sua Vertente Geológica. Braga: Palimage Editores, 2005.

CALLAI, Helena Copetti. A formação do profissional da geografia. $2^{a}$ ed. Ijuí: Unijuí, 2003.

CONFERÊNCIA GERAL DA ORGANIZAÇÃO DAS NAÇÕES UNIDAS PARA A EDUCAÇÃO, CIÊNCIA E CULTURA - UNESCO. Convenção para a Proteção do 
Patrimônio Mundial, Cultural e Natural. 1972, 16 p. Disponível em: <http://whc.unesco.org/archive/convention-pt.pdf>. Acesso em: 10 mai. 2015.

DELPHIM, Carlos Fernando de Moura. O Patrimônio Natural no Brasil. IPHAN - Instituto do Patrimônio Histórico e Artístico Nacional. Rio de Janeiro, 2004. Disponível em:< http://portal.iphan.gov.br/uploads/publicacao/Patrimonio_Natural_no_Brasil.pdf >. Acesso em: 12 mai. 2015.

FLORÊNCIO, Sônia Rampim; CLEROT, Pedro; BEZERRA Janaína; RAMASSOTE Rodrigo. Educação Patrimonial: histórico, conceitos e processos. IPHAN, 2014. Disponível em: 〈http://portal.iphan.gov.br/uploads/ckfinder/arquivos/Educacao_Patrimonial.pdf>.

Acesso em: 02 abr. 2015.

INSTITUTO DO PATRIMÔNIO HISTÓRICO E ARTÍSTICO NACIONAL - IPHAN.

Patrimônio Cultural. Disponível em: <http://portal.iphan.gov.br/pagina/detalhes/218>. Acesso em: 02 abr. 2015.

INSTITUTO BRASILEIRO DE GEOGRAFIA E ESTATÍSTICA - IBGE. IBGE Cidades. Disponível em:

<http://www.cidades.ibge.gov.br/painel/painel.php?codmun=291770\&search=bahialj aguarari|infograficos:-dados-gerais-do-municipio\&lang=>. Acesso em: 02 mai. 2015.

INSTITUTO BRASILEIRO DE GEOGRAFIA E ESTATÍSTICA - IBGE. I Centenário das Ferrovias Brasileiras. Diversos Autores. Rio de Janeiro: Serviço Geográfico do Instituto Brasileiro de Geografia e Estatística, 1954, p. 1- 86. Disponível em: < https://archive.org/details/centenarioferrovias1954>. Acesso em: 23 mai. 2015. JATOBÁ, L.; LINS, R. C. Introdução à Geomorfologia. $3^{\text {a }}$ ed. Recife: Bagaço, 2008. MOREIRA, Jasmine Cardozo. Geoturismo: uma abordagem histórico-conceitual. Campinas, SeTur/SBE. Turismo e Paisagens Cársticas, v. 3, n. 1, p. 5-10, jun. 2010. Disponível em: < http://www.sbe.com.br/ptpc/tpc_v3_n1_005-010.pdf>. Acesso em: 10 mai. 2015.

NEVES, Karina Fernanda Travagim Viturino. Os trabalhos de campo no ensino de geografia: reflexões sobre a prática docente na educação básica. Ilhéus: Editus, 2010. NASCIMENTO, Marcos Antônio Leite do; RUCHKYS, Úrsula Azevedo;

MANTESSONETO, Virgílio. Geoturismo: um novo segmento do turismo no Brasil. Global Tourism, v. 03, n. 2, p. 1-24, nov. 2007. Disponível em: <

http://www.publicacoesdeturismo.com.br/ref.php?id=806>. Acesso em: 08 mai. 2015. LOPES, Laryssa Sheydder de Oliveira; ARAÚJO, José Luís Lopes. Princípios e estratégias de geoconservação. OBSERVATORIUM: Revista Eletrônica de Geografia, v.3, n.7, p. 6678, out. 2011. Disponível em: 〈http://www.observatorium.ig.ufu.br/pdfs/3edicao/n7/5.pdf >. Acesso em: 08 mai. 2015.

LOPES, Laryssa Sheydder Oliveira; ARAÚJO, José Lopes; CASTRO, Alberto Jorge Farias. Geoturismo: Estratégia de Geoconservação e de Desenvolvimento Local. Caderno de

Geografia, v.21, n.35, p. 1-11, jan./jun. 2011. Disponível em:

$<$ http://periodicos.pucminas.br/index.php/geografia/article/view/2069/2414>. Acesso em: 08 mai. 2015.

PREFEITURA MUNICIPAL DE JAGUARARI. História do município. Disponível em: <http://www.jaguarari.ba.gov.br>. Acesso em: 02 jun. 2015.

SANTURIAN, Alexandre. As Ferrovias da Bahia: Estrada de ferro Bahia ao São Francisco. 1991. Disponível em: <http://vfco.brazilia.jor.br/ferrovias/Bahia/01bahiaEFBSF.shtml>. Acesso em: 05 jun. 2015. 
. As Ferrovias da Bahia: Estrada de ferro Petrolina a Teresina. 1991. Disponível em: <http://vfco.brazilia.jor.br/ferrovias/Bahia/05bahiaEFPT.shtml>. Acesso em: 05 jun. 2015.

SOUSA, Márcia Evangelista. Mapeamento geomorfológico das cristas quartzíticas do povoado do Flamengo, Jaguarari-BA. 2013. 44f. Monografia (Graduação em Geografia). Universidade de Pernambuco, Petrolina, 2013.

SOUSA, M. E. Práticas de campo em educação patrimonial: Proposta para o povoado do Flamengo, Jaguarari-BA. 2015. 42f. Monografia (Especialização em Ensino de Geografia). Universidade de Pernambuco, Petrolina, 2015.

UNESCO - Organização das Nações Unidas para a Educação, a Ciência e a Cultura. World Heritage Education Programme. Paris - France, 1994. Disponível em: <

file://C:/Users/GT/Downloads/activity-829-1.pdf>. Acesso em: 05 mai. 2015.

ZACCHI, Giancarlo Philippi. Turismo ecológico e ecoturismo: diferenças e princípios éticos. Diálogos \& Ciência -- Revista Eletrônica da Faculdade de Tecnologia e Ciências de Feira de Santana. Ano II, n. 4, jun. 2004. Disponível em: <http://www.ftc.br/revistafsa>. Acesso em: 10 jun. 2015.

Recebido em 25 de agosto de 2018. Aceito em 01 de outubro de 2018. 